\title{
THERMOPHYSICAL PROPERTIES OF COPPER - CARBON FIBRE COMPOSITE
}

In this paper two main properties of copper matrix - carbon fibre composite from the point of view of using it in electronics as a material able to dissipate the heat are presented. Thermal expansion and thermal conductivity of the composite can be changed in dependence on volume amount of fibres in composite, their geometrical arrangement and on the properties of carbon fibres. Propagation of heat across the composite was measured. Results are in good agreement with those obtained by finite elements method calculation.

\section{Introduction}

Development of new, better and more responsible products and facilities involves demand of new materials with improved properties. Among the materials fulfilling such demands belong also composite materials.

The principle of composite materials consists in fact that by the combination of two or more dissimilar materials into one unit we can obtain material with a property, or properties, which no one of the components possesses. Combination of copper which is characterised by high thermal and electrical conductivity, high density and carbon fibres which are characterised by high strength, high modulus of elasticity, low density and low, even negative coefficient of thermal expansion (CTE) can give a material with relatively high thermal conductivity, low thermal expansion and low density which can be utilised in electronic industry as heat sink, packaging for high voltage chips, cooling plate for microwave application and carrier plate which serve for heat dissipation. The coefficient of thermal expansion as well as thermal conductivity of copper-carbon fibre $\left(\mathrm{Cu}-\mathrm{C}_{\mathrm{f}}\right)$ composites can be tailored according to the requirement by volume fraction of carbon fibres, by using carbon fibre with appropriate thermal conductivity and Young modulus and by changing the orientation of carbon fibre in copper matrix.

The aim of this paper is to characterise thermal expansion and thermal conductivity of copper-carbon fibre composites in dependence on the volume amount of fibre in composites and their geometrical arrangement. A method, calculation and measurement of heat transport across the composite to increase the transverse thermal conductivity of $\mathrm{Cu}-\mathrm{C}_{\mathrm{f}}$ composite are also discussed.

\section{Experiment}

$\mathrm{Cu}-\mathrm{C}_{\mathrm{f}}$ composites are made from Torayca $\mathrm{T} 300$ carbon fibre with 3000 monofilaments in tow. The fibres were coated by copper

\section{* Pavol Šebo, Pavol Štefánik}

Institute of Materials and Machine Mechanics, Slovak Academy of Sciences, Račianska 75, 83102 Bratislava, Slovakia, E-mail: ummssebo@savba.sk to the thickness of around $1 \mu \mathrm{m}$. Thickness of $\mathrm{Cu}$ coating gives volume of copper amount in composite. Composite can be made by diffusion bonding of unidirectionally oriented fibres producing thus monolayers of the thickness $\sim 0.2 \mathrm{~mm}$ or by weaving copper coated carbon fibres. Another type of composite can be spiral or tube arrangement of copper coated carbon fibres [1].

Properties of unidirectional composites are anisotropic because of anisotropic properties of carbon fibres. To lower this anisotropy cross-ply arrangement of monolayers was used. Another type of composite with lower stress between the cross-ply monolayers due to anisotropy in thermal expansion was prepared using copper foils in-between perpendicularly oriented monolayers. Schematic view of various arrangements of fibres in $\mathrm{Cu}-\mathrm{C}_{\mathrm{f}}$ composites can be seen in Fig. 1. Some properties of selected carbon fibre as well as some metal (for comparison) are presented in Table 1.

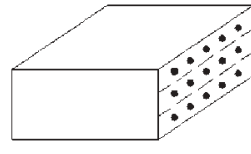

a

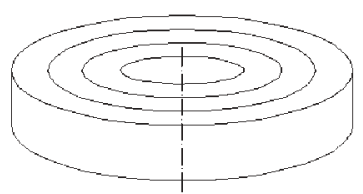

C

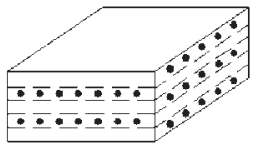

b

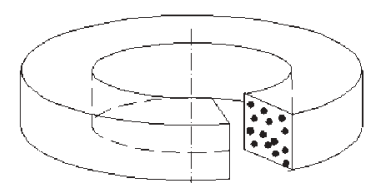

d
Fig. 1. Scheme of various arrangement of fibres in $\mathrm{Cu}$ - $C_{f}$ composites: (a) unidirectional, (b) cross-ply, (c) spiral and (d) tubular. 
Some properties of selected carbon fibres and several metals.

\begin{tabular}{|c|c|c|c|c|c|}
\hline Material & $\begin{array}{c}\text { Density } \\
{\left[\mathrm{kgm}^{-3}\right]}\end{array}$ & $\begin{array}{c}\text { Strength } \\
{[\mathrm{GPa}]}\end{array}$ & $\begin{array}{c}\text { Young } \\
\text { modulus } \\
{[\mathrm{GPa}]}\end{array}$ & $\begin{array}{c}\text { Thermal } \\
\text { conductivity } \\
{\left[\mathrm{Wm}^{-1} \mathrm{~K}^{-1}\right]}\end{array}$ & $\begin{array}{c}\mathrm{CTE} \\
{\left[10^{-6} \mathrm{~K}^{-1}\right]}\end{array}$ \\
\hline $\mathrm{Al}$ & 2700 & 0.08 & 69.5 & 237 & 24 \\
\hline $\mathrm{Cu}$ & 8960 & 0.2 & 125 & 400 & 17.5 \\
\hline Steel & 8260 & 3.8 & 210 & 48 & 11.7 \\
\hline $\mathrm{C}_{\mathrm{f}}$ T300 & 1760 & 3.6 & 231 & 5 & -0.5 \\
\hline $\mathrm{C}_{\mathrm{f}}$ P120S & 2180 & 2.2 & 827 & 640 & -1.44 \\
\hline $\mathrm{C}_{\mathrm{f}}$ K3D2U & 2200 & 3.7 & 935 & 800 & \\
\hline $\mathrm{C}_{\mathrm{f}}$ K1100X & 2200 & 3.1 & 956 & 1060 & -1.4 \\
\hline VGCF & & & & 1500 & \\
\hline
\end{tabular}

\section{Results and discussion}

\subsection{Thermal expansion}

A large number of models for prediction of thermal expansion was developed. For longitudinal (L) coefficient of thermal expansion (CTE) of two phases composite Shapery [2] derived an equation

$$
\alpha_{C L}=\frac{\alpha_{F L} V_{F} E_{F L}+\alpha_{M}\left(1-V_{F}\right) E_{M}}{V_{F} E_{F L}+E_{M}\left(1-V_{F}\right)}
$$

for transverse (T) CTE we used equation

$$
\begin{aligned}
\alpha_{C T}= & \left(1-V_{F}\right)\left(1+\nu_{M}\right) \cdot \\
\cdot & \left(M+V_{F}\left(1+\nu_{F L}\right) \alpha_{F T}-\nu_{C} \nu_{C L}\right.
\end{aligned}
$$

where $\alpha, V, E, \nu$ are CTE, volume fraction, Young modulus and Poisson number, indices $C, M, F, L$ and $T$ are for composite, matrix, fibre, longitudinal and transverse direction, respectively.

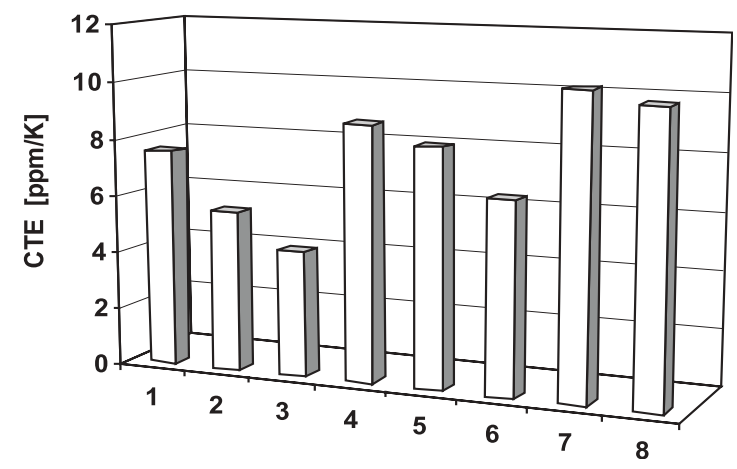

Fig. 2. Coefficient of thermal expansion of $\mathrm{Cu}-C_{f}$ composite for various fibre arrangement.

(1), (2), (3) unidirectional (in fibre direction) with 40, 50 and $60 \mathrm{vol. \%}$ carbon fibre, respectively, (4), (5), (6) cross-ply with 47, 50 and 57 vol.\% $C_{f}$, respectively and (7), (8) woven composite with 47 vol. $\% C_{f}$ in $x$ and $y$ directions, respectively.
The measurement of CTE was performed in push-rod dilatometer [3]. Unidirectional specimens were measured in direction parallel and perpendicular to the fibre orientation and cross-ply and woven samples were measured in the direction along the fibres and in transverse direction (perpendicularly to the fibre plane).

The results obtained by measurement of CTE for various fibre amount and various geometrical arrangement of fibre are summarised in Fig. 2. As can be seen from Fig. 2 these values of CTE can be tailored by selection of proper fibre amount, and their arrangement. The mean CTE of $\mathrm{Cu}-\mathrm{C}_{\mathrm{f}}$ composite should be in the range of (4 - 9) $\times 10^{-6} \mathrm{~K}^{-1}$ to match the one of the electronic materials e.g. $\mathrm{Si}\left(\alpha=4.1 \times 10^{-6} \mathrm{~K}^{-1}\right), \mathrm{Al}_{2} \mathrm{O}_{3}\left(\alpha=6.5 \times 10^{-6} \mathrm{~K}^{-1}\right)$. As it can be seen in Fig. 2 the cross-ply and woven composites of appropriate fibre content are candidate materials for the heat sinks and packaging plate application.

\subsection{Thermal conductivity}

Copper-carbon fibre composite as an anisotropic two components material possesses two thermal conductivities - longitudinal and transverse. Longitudinal thermal conductivity can be expressed by rule of mixtures.

$$
\lambda_{C L}=\lambda_{F L} V_{F}+\lambda_{M}\left(1-V_{F}\right)
$$

transverse thermal conductivity $\lambda_{C T}$ of unidirectional composite was derived by Hatta and Taya [5]

$$
\lambda_{C T}=\lambda_{M} \frac{\lambda_{M}\left(\lambda_{F T}-\lambda_{M}\right) V_{F}}{\lambda_{M}+\left(1-V_{F}\right)\left(\left(F_{T}-\lambda_{M}\right) / 2\right.}
$$

where $\lambda$ and $V$ are thermal conductivity and volume amount, respectively and indices $C, L, T, F, M$ are for composite, longitudinal, transverse, fibre and matrix, respectively.

Thermal conductivity was measured by laser flash method. The method measures the thermal diffusivity of a material and thermal conductivity is calculated according to

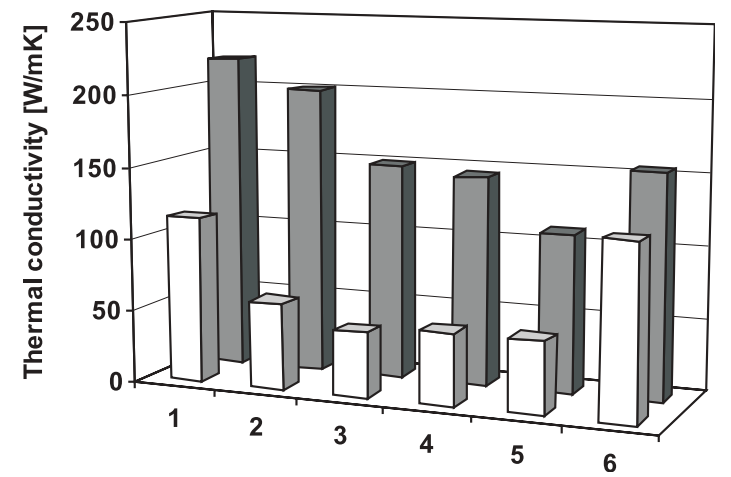

Fig. 3. Thermal conductivity of $\mathrm{Cu}-\mathrm{C}_{f}$ composite in longitudinal (rear line) and transverse (front line) for various fibre arrangement: (1), (2),

(3) unidirectional with 40, 50 and $60 \mathrm{vol} . \% C_{f}$, respectively, (4), (5) cross-ply with 50 and $60 \mathrm{vol} . \% C_{f}$ and (6) woven with $40 \mathrm{vol} . \%$. 


$$
\lambda=a c_{p} \rho
$$

where $c_{p}$ and $\rho$ are specific heat and density of a material.

Thermal conductivity of $\mathrm{Cu}-\mathrm{C}_{\mathrm{f}}$ composite in longitudinal (rear) and transverse (front line) direction for various fibre arrangements is in Fig. 3.

The required thermal conductivity of a heat sink material given by an end user, is at least $150 \mathrm{Wm}^{-1} \mathrm{~K}^{-1}$. As can be seen from the presented results the transverse thermal conductivity is very low. This direction of thermal conductivity is for heat dissipation in electronic packaging the most important. From the CTE point of view the most suitable composite for heat sink application are woven or cross ply composites with 45 vol.\% of fibres.

In real construction the heat is scattered not only in $z$ (transverse) direction but also in $x, y$ plane and heat sink insure the cooling practically from whole of its opposite surface.

To understand the propagation of heat in composite material we measured the temperatures in several surface points of composite. Halogen lamp gives a heat through glass bar, which produces, round light area of a diameter $10 \mathrm{~mm}$ in the centre of specimen of dimension $50 \times 50 \times 1 \mathrm{~mm}$ [7]. Propagation of heat was measured by thermocouples in various distance from the centre of specimen with perpendicular and parallel direction to fibres. Accuracy of the apparatus was tested on homogeneous copper plate. Obtained results were compared with the calculation of the temperature distribution by finite elements method using the software ANSYS [8].

Typical curves showing dependence of temperature on time for $\mathrm{Cu}-\mathrm{C}_{\mathrm{f}}$ composites containing 40 vol.\% fibres are in Figs. $4 \mathrm{a}, \mathrm{b}$. Thin lines are experimental results, thick lines are for calculated dependencies for the same specimen. The digits in the brackets (co-ordinates) give distance (in $\mathrm{mm}$ ) of thermocouples location from the centre of the sample. Co-ordinate $z=0$ means the front of the sample, $z=1$ means back side of the specimen.

Comparison of experimental and calculated results gives the density of heat flux around $16000 \mathrm{Wm}^{-2}$. Temperature increasing in composite with unidirectionally arranged fibres in the amount of $40 \mathrm{vol} . \%$ in the same distance from the centre of the specimen is approximately equal to that one in homogeneous material. For higher amount of fibres in composite ( $63 \mathrm{vol} . \%)$ the temperature increasing in fibre direction is more expressive where low thermal conductivity of fibres in transverse direction has already been manifested.

Increasing the in-plane and transverse thermal conductivity of the composite can be generally achieved by adding as much as possible the highest thermal conductive material, in our case of copper, taking into account technological problems as well as the influence of copper on other properties of composite, e.g. CTE. Ting, Lake and Duffy [6] developed vapour grown carbon fibre (VGCF) as reinforcement in carbon and aluminium matrices for
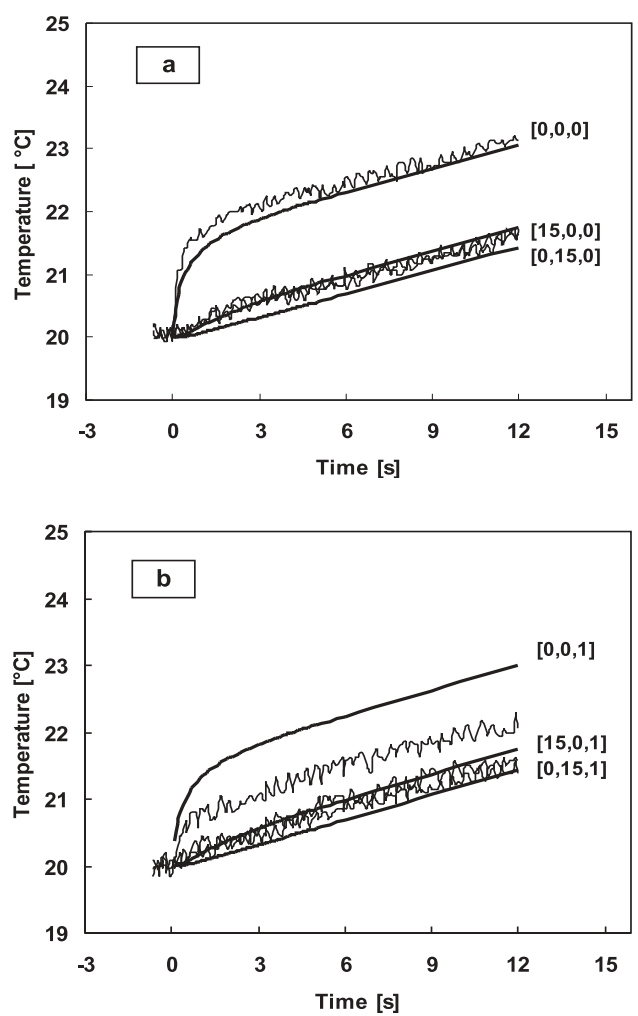

Fig.4. Experimental (thin) and calculated (thick line) temperature dependence on time of heating of $\mathrm{Cu}-\mathrm{C}_{f}$ composite with $40 \mathrm{vol} . \%$ fibres. (a) front, (b) back side of the specimen.

thermal management. Thermal conductivity of $\mathrm{Al}$ matrix composite with 36.5 vol.\% VGCF was $642 \mathrm{Wm}^{-1} \mathrm{~K}^{-1}$ and that one with carbon matrix was $910 \mathrm{Wm}^{-1} \mathrm{~K}^{-1}$.

The increase of thermal conductivity of $\mathrm{Cu}-\mathrm{C}_{\mathrm{f}}$ composite can be done in several ways [7]

- using carbon fibre with high axial thermal conductivity

(a)

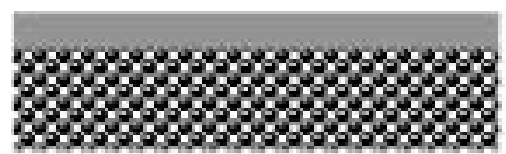

(b)

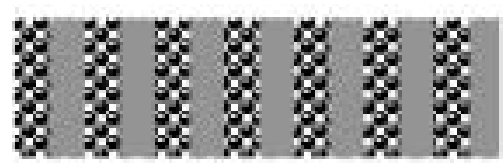

(c)

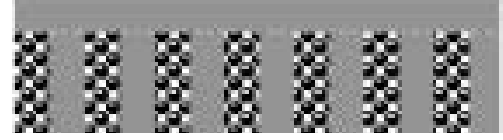

Fig. 5. Scheme of Cu elements in composite: (a) foils, (b) bridges, (c) foil and bridges. 
- coating skeleton of carbon fibres with high conductive carbon by chemical vapour deposition followed by pressure infiltration of copper

- adding the $\mathrm{Cu}$ foils on the surface of $\mathrm{Cu}-\mathrm{C}_{\mathrm{f}}$ composite to increase in-plane thermal conductivity (Fig. 5a)

- constructing copper bridges in transverse direction (Fig. 5b)

- combining last two points to increase both longitudinal and transverse thermal conductivity (Fig. 5c)

First experiments concerning the increase of transverse thermal conductivity by construction of copper bridges (Fig. 5b) were done and preliminary results were obtained [10].

\section{Conclusion}

The obtained results demonstrate the possibility of preparing copper matrix - carbon fibre composite material with the proper- ties suitable for using it as heat dissipation material. The coefficient of thermal expansion can be controlled in the interval of $(4-9) \times 10^{-6} \mathrm{~K}^{-1}$. Thermal conductivity in longitudinal direction in the interval of $(100-220) \mathrm{Wm}^{-1} \mathrm{~K}^{-1}$ and in transverse direction of $(50-100) \mathrm{Wm}^{-1} \mathrm{~K}^{-1}$ in dependence on the amount of fibres and their arrangement in composite. To increase the transverse thermal conductivity, propagation of heat across the composite was measured in dependence on volume amount of fibres. For low volume amount ( $40 \%$ ) of fibres the heat dissipation is close to that of homogeneous material, for higher amount ( $63 \%)$ of fibres the temperature increase is higher in all measured points. The results are very close to the results obtained by finite elements method calculation.

\section{References}

[1] ŠEBO, P., ŠTEFÁNIK, P.: Inter. J. Mater. Product Technology 18, 2003, pp. 141-159.

[2] SHAPERY, R. A.: J. Comp. Mater. 2, 1968, pp. 380-404.

[3] KORÁB, J.: Ph.D.Thesis, Technical University, Wien, 1999.

[4] KORÁB, J., ŠTEFÁNIK, P., ŠEBO, P., KAVECKÝ, Š.: Proc. 6th Internat. Conf. Technológia '99, Bratislava, Sept. 8-9, 1999, pp. 96-99.

[5] HATTA, H., TAYA, M.: J. Appl. Phys. 59, 1986, pp. 1851-1860.

[6] TING, J. M., LAKE, M. L., DUFFY, D. R.: J. Mater. Res. 10, 1995, pp. 1478-1484.

[7] HUdCOVIČ, P., ŠTEFÁNIK, P., VOZÁR, L.: Proc. 9th Internat. Conf. CO-MA-TECH 2001, Trnava, Oct.25-26, 2001, pp. 80-85.

[8] ŠTEFÁNIK, P., BEHÚlOVÁ, M., HUDCOVIČ, P.: Proc. 4th Conf. Konštrukčné materiály 2003, Bratislava, May 6, 2003, pp. 16-22.

[9] HUDCOVIČ, P., VOZÁR, L., ŠTEFÁNIK, P.: Proc. Thermophysics 2001, Račkova dolina, Oct.23, 2003, pp. 49-54.

[10] KAVECKÝ, Š., ŠTEFÁNIK, P., ŠEBO, P.: Proc. 4th Conf. Konštrukčné materiály 2003, Bratislava, May 6, 2003, pp. 10-15. 